\title{
BRASIL-ÍNDIA PÓS-1990: UMA ANÁLISE DAS RELAÇÕES COMERCIAIS E DE COOPERAÇÃO
}

\section{Brazil-India Post-1990: An Analysis Of Trade Relations And Cooperation}

Jacqueline A Haffner ${ }^{1}$

Mirela Ribeiro Kosminsky ${ }^{2}$

\section{Introdução}

A partir da década de 1990, com o fim da Guerra Fria e com a emergência de um mundo cada vez mais multipolar, observa-se um movimento das potências médias, como o Brasil, no sentido de diversificar seus parceiros estratégicos com o objetivo de minimizar vulnerabilidades sistêmicas e maximizar sua influência no sistema internacional. Nesse contexto, a cooperação Sul-Sul vem se tornando cada vez mais recorrente, uma vez que as chamadas potências emergentes passam a compartilhar objetivos e mecanismos para solução de problemas comuns. É neste âmbito que se dá a aproximação brasileira com a Îndia, marcada também por uma mudança significativa do paradigma de inserção internacional dos dois países, a partir de uma série de reformas liberalizantes realizadas nas economias brasileira e indiana no início da década de 1990.

Assim, o este trabalho se propõe a analisar a evolução das relações entre Brasil e Îndia após a abertura comercial destes países, a partir de princípios da década de 1990, considerando aspectos comerciais e político-diplomáticos deste relacionamento, nos âmbitos bilateral e multilateral. Para isso, pretende-se levantar dados sobre as relações comerciais dos dois países nas últimas duas décadas, traçando um histórico das relações indo-brasileiras através da análise da pauta de exportações entre os dois países. No que tange à cooperação política, serão analisados acordos, tratados e comunicados conjuntos que permitem construir um histórico do relacionamento.

Este artigo está dividido em quatro seções, incluindo esta introdução e a conclusão. A segunda seção trata dos aspectos comerciais do relacionamento entre os dois países entre 1990 e 2009, enquanto a terceira seção se refere à análise das iniciativas de cooperação política - contemplando tanto o aspecto bilateral

\footnotetext{
${ }^{1}$ Economista. Professora do Departamento de Economia e Relações Internacionais (DERI) e do Programa de Pós-graduação em Estudos Estratégicos Internacionais (PPGEEI) da Universidade Federal do Rio Grande do Sul (UFRGS). Integrante do Grupo de Pesquisa sobre os BRICS (NEBRICS-UFRGS). (jacqueline.haffner@ufrgs.br).

${ }^{2}$ Bacharel em Relações Internacionais, Formada pelo Departamento de Economia e Relações Internacionais (DERI) da Universidade Federal do Rio Grande do Sul (UFRGS). (mirelakosminsky@gmail.com).
} 
quanto a atuação em organismos multilaterais, notadamente no IBAS e no BRICS. Por fim, apresentam-se as considerações finais deste artigo.

\section{Esforços De Aproximação Entre Os Dois Países}

As relações tanto econômicas quanto políticas estabelecidas entre Brasil e Índia têm se expandido de forma crescente. Cada dia mais, os dois países têm transcendido sua mera condição de semelhança (subdesenvolvimento, posição sul, tamanho, população, etc.) para atingir uma identificação e complementaridade bastante grande.

Sua relação, antes apenas baseada em elementos econômicos, é agora composta por um caráter político. Diversos acordos têm sido formalizados e a tendência é que de agora em diante haja um aumento nestes acordos e sua relação seja cada vez mais pautada por uma cooperação sul-sul. Esta nova situação entre os dois países se viu forçada a partir dos problemas econômicos enfrentados ao longo da década de 1980, a Índia foi obrigada a buscar um novo posicionamento no sistema internacional, adotando uma postura mais aberta e "globalista" em relação ao comércio e à sua economia (HAFFNER; MONTEIRO, 2011).

Com o fim da União Soviética, que representava um parceiro comercial importante para a Índia, muitos dirigentes indianos começaram a considerar a América Latina como uma alternativa para preencher este espaço. Neste contexto, o Brasil passou a receber atenção especial, justamente por ser o país com maior potencial de comércio na região.

Deste modo, a partir de 1992, podemos observar uma série de iniciativas indianas de demonstrar interesse e cortesia ao Brasil, como a presença do Ministro de Relações Exteriores indiano, Eduardo Faleiro, na posse do presidente Fernando Collor de Mello. Estes esforços de aproximação por parte da Índia foram notáveis ao longo da primeira metade da década de 1990.

Neste período também se destaca a assinatura de alguns acordos de cooperação tecnológica e política, entre eles o Memorando de Entendimento Relativo a Consultas sobre Assuntos de Interesse Comum, em 1992, e o Ajuste Complementar ao Acordo de Cooperação nos Campos da Ciência e Tecnologia, sobre Cooperação Científica e Tecnológica no Setor Ferroviário, em 1993. É o começo da institucionalização das relações bilaterais entre os dois países.

Um fato relevante, que acabou por aproximar comercialmente os dois países, foi a quebra na safra de cana de açúcar na Índia em $1994^{3}$ - o que pode ser considerado favorável ao comércio brasileiro, que naquele ano exportou 621 milhões de dólares para o mercado indiano, sendo 69,8\% referente ao açúcar e os cerca de 30\% restantes ao minério de ferro e seus derivados, óleo de soja e máquinas agrícolas. Com este resultado, a Índia se tornou o terceiro mercado asiático mais importante para o Brasil (VIEIRA, 2007).

Entretanto, este é um resultado pontual, pois, no ano seguinte, as exportações brasileiras para a Índia voltam ao patamar anterior. Enquanto isso, as importações da Índia pelo Brasil apontam tendências de crescimento durante a década de 1990, conforme mostra o Gráfico 1:

\footnotetext{
${ }^{3}$ A quebra da safra de cana-de-açúcar na Índia se deu em função da irregularidade das chuvas no ano anterior.
} 
Gráfico 1 - Comércio entre Brasil e Índia (1990-1999) em US\$ FOB 4

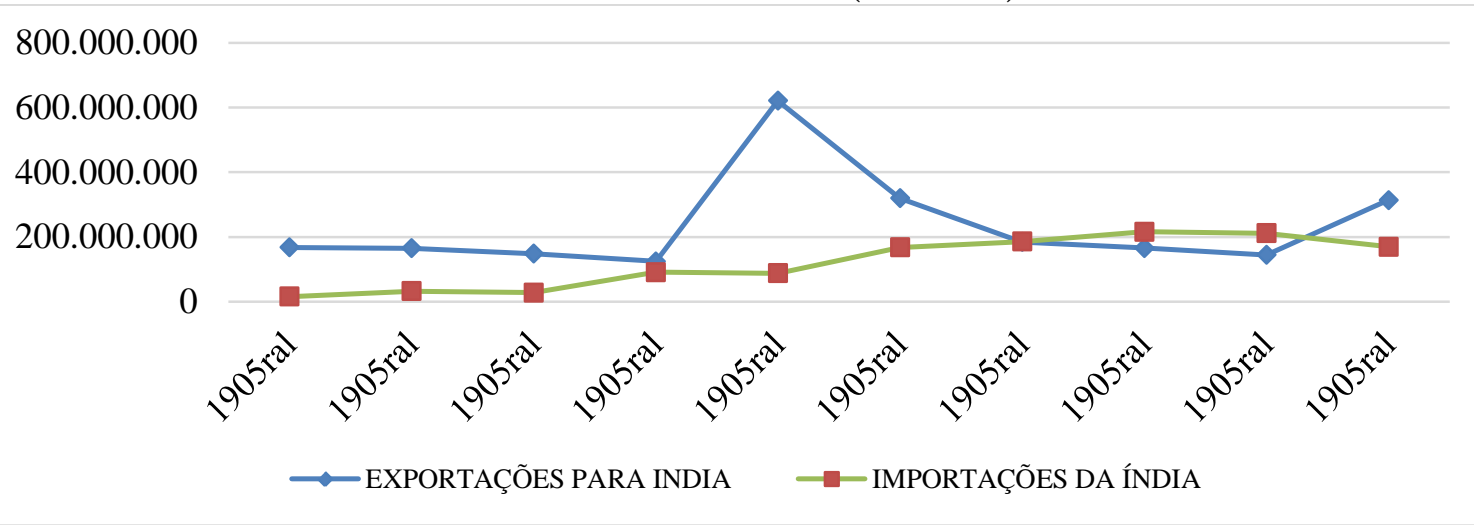

Fonte: Elaborado pelas autoras com dados do Ministério do Desenvolvimento, Indústria e Comércio Exterior (2014).

Com a exceção do pico de exportações em 1994, explicado previamente, podemos observar que a priorização do mercado brasileiro pelo governo indiano não é recíproca, resultando em um saldo deficitário para o Brasil entre 1996 e 1998, quando se percebe uma retomada do fluxo de exportações brasileiras para este país. A Índia via o Brasil como um parceiro promissor, com um potencial de negócios a ser explorado impressionante, e trabalhou efetivamente para ampliar o comércio com os mercados latino-americanos e com o Brasil.

Prova disso são os estudos para analisar a viabilidade econômica de estabelecer linhas marítimas diretas entre a Índia e a América do Sul via África do Sul, para que a rota via Europa fosse substituída. Esta nova rota reduziria significativamente custos de frete e o tempo de viagem, resultando em maior competitividade para os produtos indianos. Também se destaca a emissão crescente de vistos para empresários indianos com desejo de fazer negócios no Brasil.

Logo após a abertura econômica dos dois países no início da década de 1990, pode-se dizer que a atitude brasileira em relação ao estreitamento dos laços com a Índia foi, em sua maioria, de caráter reativo, destacando-se algumas visitas ministeriais em 1992 e 1994. A visita do presidente Fernando Henrique Cardoso à Índia em 1996 inauguraria uma nova fase do relacionamento entre os dois países, a partir da qual se percebe uma posição mais assertiva do Brasil no sentido da aproximação.

A viagem presidencial de 1996, em que Fernando Henrique Cardoso foi à Índia acompanhado do Ministro das Relações Exteriores, do Ministro da Agricultura, do Ministro da Ciência e Tecnologia e do Chefe da Casa Militar, marca o início de uma “[...] fase de deliberada construção de uma relação diversificada e intensa.” (BRASEMB NOVA DELHI, 199855,). Assim, o Brasil traçou como estratégia a identificação de um empreendimento de grande porte, que serviria para impulsionar o intercâmbio em outras áreas.

A visita seria retribuída em 1998 pelo presidente indiano Narayanan, que veio ao Brasil acompanhado de seu Ministro da Aviação Civil. Nesta ocasião, seriam assinados mais dois documentos de cooperação, um na área das Academias Diplomáticas e outro na área da Saúde e Medicina. Os dois acordos

\footnotetext{
${ }^{4}$ Free on Board: termo de comércio internacional para denominar o tipo de frete em que o comprador assume todos os riscos e custos com o transporte da mercadoria, assim que a mesma é colocada a bordo do navio. O Vendedor fica responsável pelo transporte da mercadoria até o porto de embarque designado pelo importador.

${ }^{5}$ BRASEMB NOVA DELHI [Ofício 028] 20 abr 1998, Nova Délhi [para] MRE, Brasília. 35 p. Visita do presidente Narayanan. Maço de apoio. Pg. 11.
} 
tinham um viés de formalizar intenções que vinham sendo expressas há muito tempo, mas não representam um progresso significativo, em função da diferença de entendimento das questões, principalmente na área médica.

Apesar destes avanços no relacionamento bilateral entre os dois países, o ano de 1999 seria marcado pelo esfriamento das relações entre Brasil e Índia em decorrência da crise de desvalorização do Real. Os anos 2000 se caracterizariam pela retomado do empenho dos dois países em desenvolver ações práticas que concretizassem o desejo mútuo de aproximação, que até então não se materializara de maneira efetiva.

Um aspecto importante para a aproximação dos dois países a partir de 2001 é a conjuntura de comércio exterior na qual a Îndia está inserida, que acabou por reforçar as vantagens para os países latinoamericanos. Isso se dá, principalmente, em função dos compromissos assumidos pelo governo indiano na OMC.

Estas alterações na Política de Comércio Exterior indiana podem ser consideradas o fim do processo de liberalização da economia iniciado em 1991. Como as reformas realizadas resultaram numa crescente desproteção do mercado doméstico indiano, o governo julgou necessário tomar medidas para evitar o aumento do déficit comercial do país, lançando assim incentivos financeiros às exportações. Em 2000, por exemplo, foi operacionalizada uma linha de crédito de 120 milhões de dólares destinada a estimular as exportações indianas para a América Latina.

Esta ofensiva indiana, no sentido de aumentar sua presença nos mercados da América Latina, mostrou-se um empecilho à manutenção do equilíbrio da balança comercial brasileira com a Îndia. Assim, foi necessário que o governo brasileiro agisse paralelamente ao governo indiano, estimulando seus próprios exportadores. No entanto, os incentivos oferecidos pelo Ministério do Desenvolvimento, Indústria e Comercio Exterior não tinham tantos efeitos quanto os oferecidos pelo governo da Índia a seus exportadores, somando-se ao fato de que o mercado indiano era mais protegido.

A partir dos anos 2000, também se pode observar uma certa iniciativa do setor empresarial indiano - através da Confederação das Indústrias Indianas, da Federação das Câmaras de Comércio e Indústrias Indianas e da Indian Trade Promotion Organization - em buscar o mercado brasileiro de maneira mais autônoma, e não apenas reativa, aproveitando os estímulos estatais. Essas comitivas empresariais eram compostas, majoritariamente, por exportadores, enquanto as iniciativas do setor privado brasileiro eram predominantemente de importadores (VIEIRA, 2007).

A partir do governo Lula no Brasil, o relacionamento com a Índia será intensificado, tanto em termos multilaterais - com a criação do IBAS (Índia, Brasil e África do Sul) e do G20 e a forte articulação do G4 (Índia, Brasil, Alemanha e Japão) na busca por um assento permanente no Conselho de Segurança da $\mathrm{ONU}$ - quanto em termos bilaterais.

Em 2004 foi assinado, em Nova Delhi, o Acordo de Comércio Preferencial entre o MERCOSUL e a República da Índia. A Índia foi o primeiro país fora do continente sul-americano a celebrar um acordo com o MERCOSUL. Além da importância econômica, esse acordo também possui importância política ao inserir a Índia no âmbito da América Latina, de modo a aumentar sua influência global. Por outro lado, também abre 
as portas para uma futura área de livre comércio entre os países do IBAS. O MERCOSUL é o caminho que o Brasil possui de negociar com a Índia, já que devido aos compromissos firmados com o bloco do MERCOSUL não pode fazê-lo bilateralmente (HAFFNER; BARBOSA, 2012).

Também em termos econômicos e de cooperação, uma série de acordos foram firmados entre os dois países, na esfera da pesquisa espacial, do turismo e do comércio internacional. Entre eles, se destaca o Memorando de Entendimento sobre Proteção Fitossanitária em 2006, com o objetivo de que os dois países realizassem as análises de risco de pragas necessárias para aumentar as trocas de produtos como soja, milho, algodão, frutas, carne de frango e cereais. Este documento teve um grande valor para o comércio bilateral entre Índia e Brasil, tendo em conta o crescimento acelerado da população indiana e as perspectivas que a Índia se torne, num futuro próximo, um importante importador de alimentos.

\section{Análise Histórica Da Pauta De Exportação Entre Índia E Brasil}

Historicamente, há uma aproximação comercial dos mercados brasileiro e indiano, principalmente após a abertura econômica dos dois países. Esse fenômeno, conforme discutido na seção anterior, é resultado, principalmente, de iniciativas indianas e, em menor parte, das respostas moderadas do governo brasileiro.

Como apresentado no Gráfico 1, as importações com origem indiana que chegam ao Brasil tiveram uma tendência de crescimento na década de 1990. Isso se explica pela visão prioritária do mercado latinoamericano e pelas políticas de incentivos à exportação. Entre os principais produtos importados pelo Brasil encontram-se produtos químicos orgânicos e inorgânicos; extratos tanantes e tintoriais; máquinas, aparelhos e material elétricos; peles e couros; gomas e resinas; óleos essenciais e produtos de vestuário.

Puxada pela crise da cana-de-açúcar na Índia em 1994, a exportação de açúcar pelo Brasil é a mais expressiva no período, mas, também destaca-se a exportação de ferro fundido e aço; plásticos; minérios e gorduras animais ou vegetais.

Mesmo em função dos fortes incentivos para os exportadores indianos com desejo de se inserir no mercado latino-americano, o saldo da balança comercial do Brasil em relação à Índia se mostra superavitário na maior parte do período, conforme indica a Gráfico 2:

Gráfico 2 - Saldo da Balança Comercial do Brasil em Relação à Índia (1990-1999) em US\$ FOB

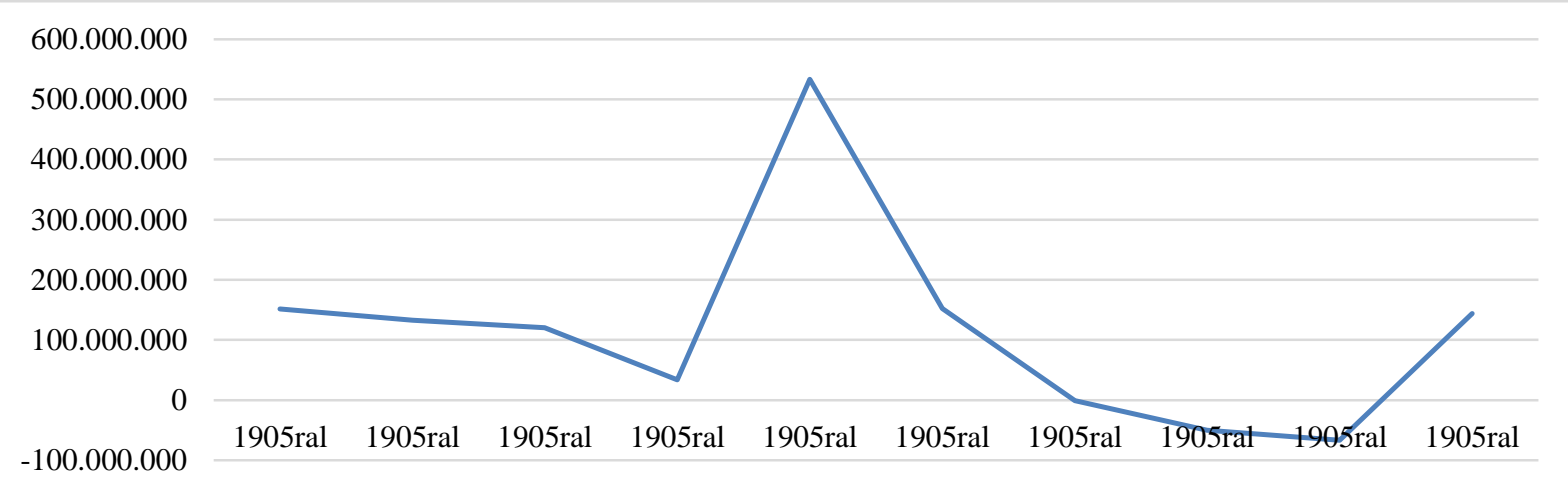

Fonte: Elaborado pelas autoras com dados do Ministério do Desenvolvimento, Indústria e Comércio Exterior (2014) 
O Gráfico 3 mostra a evolução da corrente de comércio entre Brasil e Índia no período de 1990 a 1999. Desconsiderando a anomalia de 1994, o que se percebe é uma tendência de crescimento no comércio entre os dois países, corroborando a hipótese de uma maior aproximação comercial do Brasil com a Índia após a abertura econômica destes países.

Gráfico 3: Corrente de Comércio entre Brasil e Índia (1990-1999) em US\$ FOB

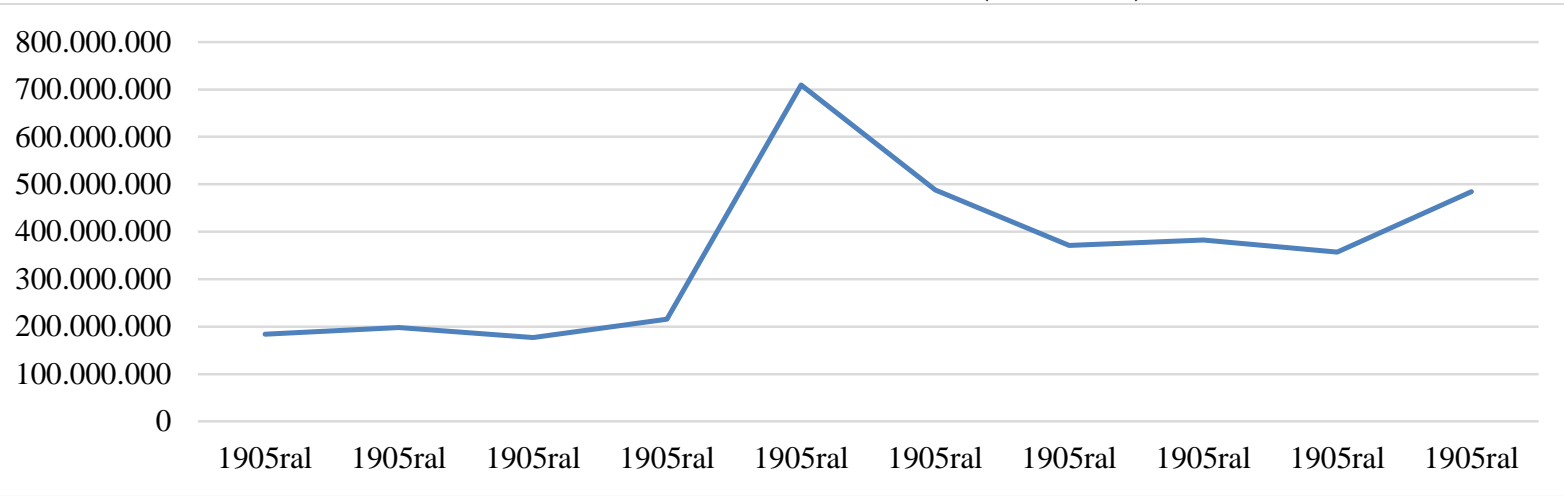

Fonte: Elaborado pelas autoras com dados do Ministério do Desenvolvimento, Indústria e Comércio Exterior (2014)

No período posterior, com a mudança da conjuntura indiana em razão dos compromissos assumidos na OMC, o comércio indo-brasileiro será alterado e, de certa forma, fortalecido. Como foi discutido na seção anterior, os incentivos do governo indiano também se intensificam no novo milênio, o que resulta em uma nova Política de Comércio Exterior da Índia. Estes dados podem ser apreciados no Gráfico 4, que apresenta dados do comércio entre Brasil e a Índia entre 2000 e 2009:

Gráfico 4 - Comércio entre Brasil e Índia (2000-2009) em US\$ FOB

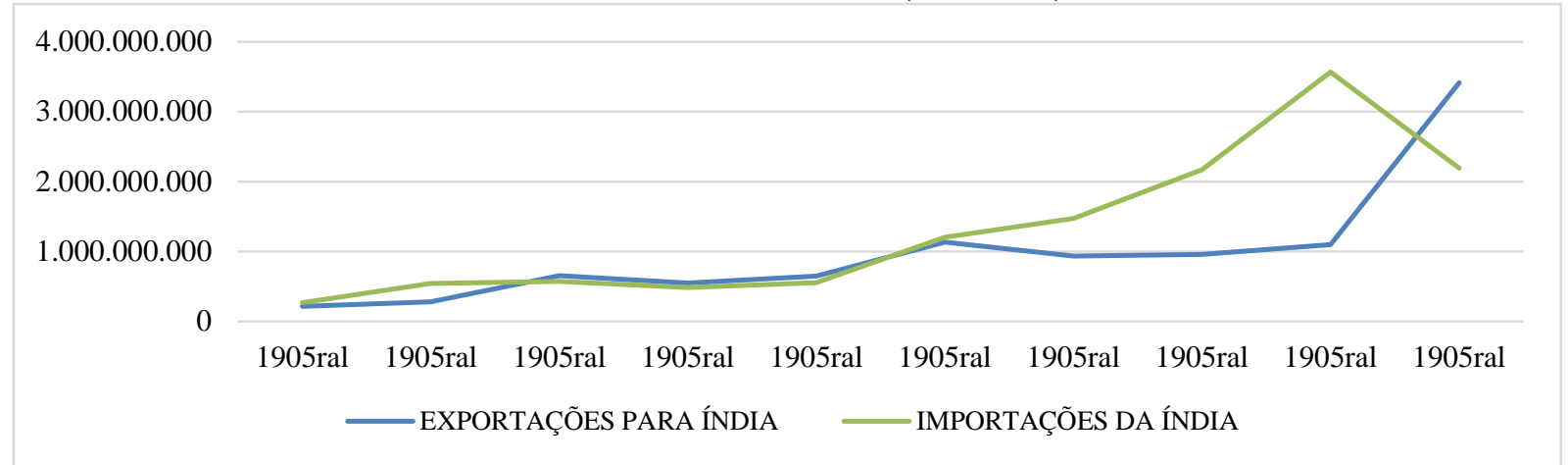

Fonte: Elaborado pelas autoras com dados do Ministério do Desenvolvimento, Indústria e Comércio Exterior (2014)

Analisando o Gráfico 4, podemos observar que a escala dos fluxos de comércio entre Brasil e Índia entre os anos de 2000 e 2009 é significativamente maior que no período anterior, mas a tendência de crescimento, em geral, se mantém, com destaque para uma maior aceleração das importações com origem indiana.

A pauta das exportações brasileiras para a Índia se mantém, de maneira geral, a mesma do período anterior. Os principais produtos continuam sendo açúcar; gorduras e óleos animais ou vegetais; minérios; ferro fundido e aço e produtos químicos; chama a atenção, porém, a crescente exportação de combustíveis e óleos minerais. 
A pauta de importações brasileiras a partir da Índia, por sua vez, se altera significativamente. Destacam-se os combustíveis e óleos minerais; produtos químicos; produtos farmacêuticos; máquinas, aparelhos e materiais elétricos e filamentos sintéticos ou artificiais. O algodão e as fibras sintéticas também aparecem com relativo destaque.

Neste contexto, cabe destacar um setor especifico, de grande relevância para os dois países: o comércio de fármacos interessava a ambos os governos e teve importância significativa no período. Como as margens de lucro no mercado interno indiano são controladas pelo governo, os laboratórios indianos consideram os mercados externos muito mais vantajosos; ao mesmo tempo, a saída encontrada pelos fabricantes indianos agradou o governo no sentido de equilibrar a balança comercial deficitária do país. Para o governo brasileiro, a entrada dos fármacos indianos aumentaria a concorrência, diminuindo os preços praticados no Brasil; além disso, a importação de matéria prima de baixo custo fomentaria o uso e a produção de medicamentos genéricos.

O que podemos inferir com base na pauta comercial entre Brasil e Índia é que, em geral, os produtos indianos importados pelo Brasil são de maior valor agregado, enquanto os produtos brasileiros são, em sua maioria, matérias-primas ou produtos agrícolas.

Os efeitos desta diferença do perfil de produtos exportados pelo Brasil e pela Índia podem ser constatados no Gráfico 5, que apresenta o Saldo da Balança Comercial do Brasil em relação à Índia no período entre 2000 e 2009 :

Gráfico 5 - Saldo da Balança Comercial do Brasil em Relação à Índia (2000-2009) em US\$ FOB

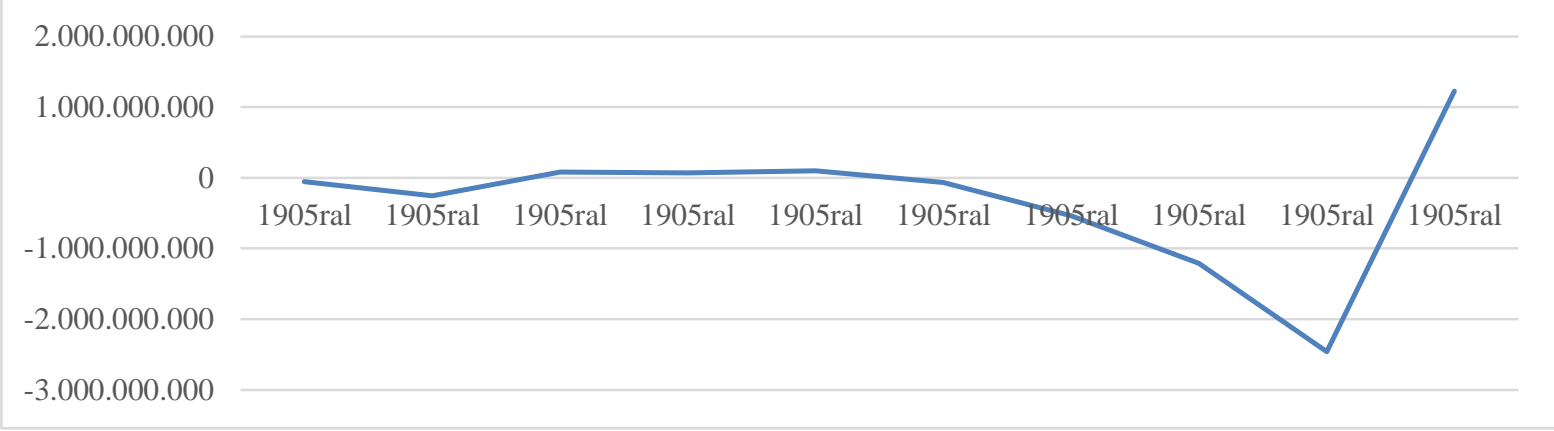

Fonte: Elaborado pelas autoras com dados do Ministério do Desenvolvimento, Indústria e Comércio Exterior (2014)

Como indica o Gráfico 5, o saldo da balança comercial do Brasil em relação à Índia no período foi, na maior parte, deficitário. Até 2005, houve um certo equilíbrio no comércio dos dois países, mas nos anos de 2006, 2007 e 2008, o déficit brasileiro foi bastante expressivo, alcançando 2,4 bilhões de dólares. Apesar disso, a curva mostra uma tendência de recuperação a partir de 2008.

No que tange à corrente de comércio entre os dois países, é interessante observar no Gráfico 6 a tendência de crescimento mais acelerada do que no período analisado anteriormente, e que, inclusive, não sofre abalos da crise econômica mundial que se inicia em 2008. Particularmente, a partir de 2004, o comércio entre os dois países se intensifica de maneira significativa, principalmente em função de iniciativas como o IBAS e o G20, que proporcionam um relacionamento mais próximo: 
Gráfico 6 - Corrente de Comércio entre Brasil e Índia (2000-2009) em US\$ FOB

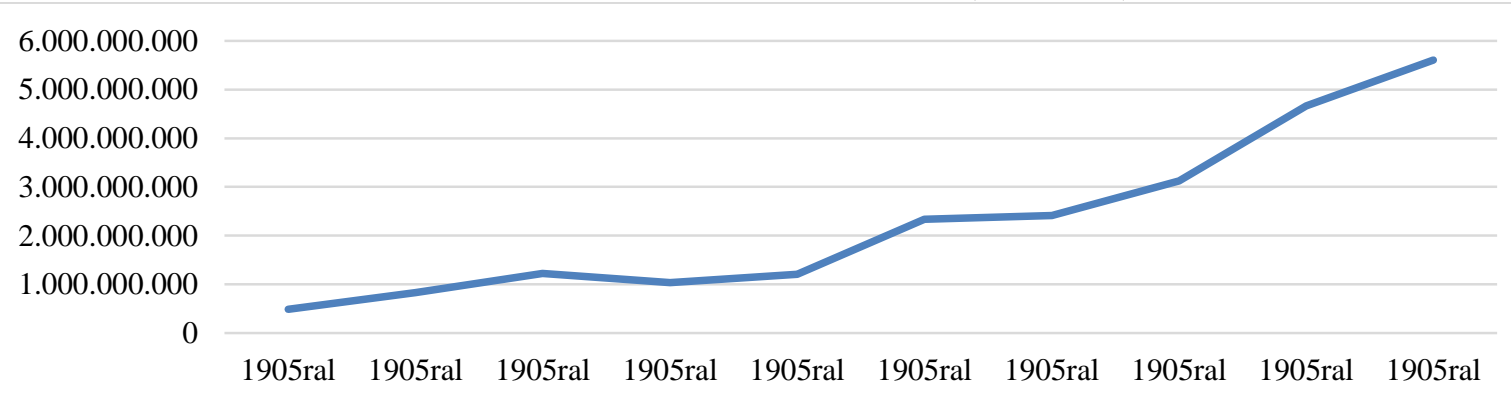

Fonte: Elaborado pela autora com dados do Ministério do Desenvolvimento, Indústria e Comércio Exterior (2014)

Com base nesta análise histórica dos fluxos de comércio entre Índia e Brasil, podemos dizer que houve uma aproximação comercial bastante intensa entre os dois países após as suas aberturas comerciais. Esta aproximação se deu de maneira mais acentuada a partir dos anos 2000, quando as reformas liberalizantes realizadas nos dois países já estarão maduras e seus mercados mais consolidados no que se refere ao comércio internacional.

Essas conclusões ficam evidentes quando observamos a corrente de comércio entre Brasil e Índia para todo o período analisado, englobando as décadas de 1990 e 2000. Os valores destes fluxos crescem com uma tendência exponencial após as aberturas das economias, atingindo números da ordem de 5,6 bilhões de dólares ao final dos anos 2000. Observa-se, desta forma, que houve uma aproximação nas relações bilaterais entre Brasil e Îndia após a abertura econômica dos dois países.

\section{Cooperação Bilateral Entre Brasil E Índia}

A perspectiva de cooperação bilateral entre Índia e Brasil não parecia óbvia no início da década de 1990. Em 1996, o então Presidente Fernando Henrique Cardoso, em um seminário de preparação a sua viagem à Îndia, concluiu que “O Brasil e a Îndia não estão necessariamente predestinados a cooperar, e que qualquer iniciativa nessa direção depende de avaliação concreta e realista do potencial de cooperação num cenário mundial em constante transformação após o fim da Guerra Fria.” (EXTERIORES, $1995^{6}$ apud VIEIRA 2007). Assim, os resultados que hoje observamos em termos de cooperação e integração entre os dois países devem ser vistos como efeitos de uma decisão deliberada pela construção de um relacionamento diversificado e intenso.

Como visto anteriormente, foi a partir da visita do Presidente Fernando Henrique Cardoso à Índia, em 1996, que as relações entre os dois países passaram a apresentar uma nova dinâmica, com uma atitude menos reativa e mais proativa por parte do Brasil. Além dos aspectos comerciais desta visita, já debatidos, ressalta-se a assinatura de uma Declaração Conjunta Brasil Índia, que expressava a elegibilidade de ambos países para um eventual Conselho de Segurança expandido. Nesta ocasião também foram assinados um memorando a respeito de Energia Nuclear - que seria denunciado pelo governo brasileiro em 1998 em função dos testes nucleares indianos - e uma Agenda Comum para o Meio-Ambiente, que tinha como

${ }^{6}$ EXTERIORES. [Circular OF0065] 15 jan 1995. Brasília [para] Brasemb, Nova Delhi. 1 p. Seminário do IPRI. 
objetivo respaldar consultas sobre as respectivas posições sobre o tema em fóruns multilaterais, tendo em mente as negociações do Protocolo de Quioto.

O contato político teve prosseguimento em 1997 com a visita à Índia da Primeira Dama Brasileira, Ruth Cardoso, com objetivo de trocar informações sobre desenvolvimento social, e com a visita ao Brasil do Ministro da Agricultura indiano, Chaturanan Mishra, com objetivo de discutir a renovação do rebanho zebuíno brasileiro. Em 1998, o Presidente indiano Narayanan veio ao Brasil, ocasião em que foram assinados memorandos de cooperação nos campos das Academias Diplomáticas, Ciência e Tecnologia e Saúde e Medicina. Todas estas iniciativas representaram: “[...] a materialização das intenções políticas de cooperação entre o Brasil e a Índia. A tônica indiana [...] dava-se em relação ao potencial incremento da corrente comercial entre os dois países.” (VIEIRA, 2007, p.80).

Tanto o governo indiano quanto o brasileiro consideravam que mitigar os problemas relativos à pobreza era essencial para promover o desenvolvimento social e econômico, através da dinamização do mercado interno e de uma maior integração de suas economias no mundo liberalizado, com a fim de diminuir os impactos negativos da globalização. Neste sentido, duas missões parlamentares brasileiras viajaram à Índia no ano 2000, com o objetivo de conhecer soluções que haviam sido aplicadas com sucesso nos problemas sociais indianos - destacando-se o programa de crédito cooperativo indiano, os instrumentos de erradicação da pobreza e projetos nas áreas de desenvolvimento rural e distribuição de alimentos.

Outro setor que entra na pauta das negociações é setor energético. De modo que, em 2001, o Ministro do Petróleo e Gás Natural, Ram Naik, visitou o Brasil para conhecer o PROALCOOL (Programa Nacional do Álcool). O que resultaria no Memorando de Entendimento Referente à Cooperação Tecnológica na Área de Mistura de Etanol em Combustíveis para Transporte, assinado em 2002, na visita do Ministro do Desenvolvimento, Indústria e Comércio Exterior, Sérgio Amaral, que somente entra em vigor em 2006 (VIEIRA, 2007).

A partir de 2003, com o início do Governo Lula e a inauguração de uma política externa mais voltada para a busca da autonomia, há uma mudança importante no relacionamento indo-brasileiro, embora os objetivos estratégicos que os governos tinham um em relação ao outro tenham sido mantidos. Isso se deve ao surgimento de uma terceira parte, representada pela África do Sul, através da formação do Fórum de Diálogo Î́ndia, Brasil e África do Sul (IBAS), que será discutido posteriormente.

Apesar da importância dos aspectos multilaterais que passam a surgir em 2003, o âmbito bilateral não deixa de ter vital importância no relacionamento entre os dois países. $O$ entusiasmo brasileiro pode ser visto como um fator de estímulo ao relacionamento, que de fato se iniciou durante o governo de Fernando Henrique Cardoso, somando-se ao fato de que Lula era considerado um líder de uma das maiores democracias do mundo e exaltado pelos seus compromissos de erradicar a fome e de tornar a ordem internacional mais democrática.

Nas relações bilaterais entre os dois países, destaca-se a realização da primeira reunião da Comissão Mista Brasil - Índia em Nova Délhi em 2003. De acordo com o Comunicado Conjunto Brasil - Índia emitido em 21 de outubro de 2003, foram criados Grupos de Trabalho em áreas de cooperação como ciência e 
tecnologia, espacial, temas sociais, saúde, energia, transportes, agricultura, turismo, comércio, cultura e educação. Além disso, o comunicado informa que "Os dois lados notaram o considerável crescimento no intercâmbio comercial bilateral, que triplicou entre 1998 e 2002, chegando a 1,2 bilhão de dólares. As estatísticas referentes a 2003 mostram que essa tendência positiva continua.” (BRASIL, 2003 - Ministério das Relações Exteriores).

Ainda no que tange à cooperação bilateral, levando em conta a similaridade dos problemas sociais enfrentados pelos dois países e a possibilidade de aprender reciprocamente com suas experiências na área social, "Os chanceleres concordaram com a necessidade de os dois países cooperarem em novas áreas, como o combate ao analfabetismo e à fome e a redução da pobreza." (BRASIL, 2003 - Ministério das Relações Exteriores).

A Comissão Mista também tratou de assuntos do campo multilateral, expressando seu apoio à reforma da ONU com objetivo de democratização do sistema internacional, além de examinar os progressos alcançados pelo IBAS e, no âmbito da OMC, pelo G20, reforçando a intenção de coordenar posições neste grupo, com objetivo de promover os interesses dos países em desenvolvimento.

A Índia, desde o discurso de posse, foi vista como uma prioridade na política externa do governo Lula, e o entusiasmo brasileiro pode ser visto como um fator de estímulo ao relacionamento, que de fato se iniciou durante o governo de Fernando Henrique Cardoso. Além disso, Lula era considerado um líder de uma das maiores democracias do mundo e exaltado pelos seus compromissos de erradicar a fome e de tornar a ordem internacional mais democrática.

Durante a visita do presidente Lula à Índia em 2004, foram realizados dois importantes eventos, sendo eles a Primeira Reunião da Agenda Comum Brasil - Índia para o Meio Ambiente e o Encontro BrasilÍndia - Desenvolvimento Sustentável: Perspectivas e Possibilidades. De acordo com o presidente Lula, em seu discurso na solenidade de abertura do encontro, o desenvolvimento sustentável, "[...] que envolve dimensões ambientais, sociais e econômicas, é hoje uma preocupação planetária. Exige a integração de diversas áreas do conhecimento humano. Pede ações em todos os países e a constante parceria entre Governos e todos os segmentos da sociedade.” (SILVA, 2004). Ainda segundo o presidente, a importância do evento, o primeiro sobre desenvolvimento sustentável realizado entre Brasil e Índia, estava justamente no maior conhecimento mútuo, na maior compreensão dos desafios e na identificação da possibilidade de parcerias: "Brasil e Índia contam com rica experiência de pesquisa em desenvolvimento sustentável e um importante acerto de projetos implantados. Dispõem de experiência na elaboração de leis de proteção ambiental e sua implementação, por vezes muito difícil.” (SILVA, 2004).

Ao longo do discurso, o presidente Lula cita como exemplo iniciativas indianas quanto brasileiras que lograram avanços no campo do desenvolvimento sustentável, condicionando a inserção internacional de ambos países à capacidade de “[...] vencer a exclusão social, a fome e o desemprego" (SILVA, 2004).

Pode-se dizer que muitos dos assuntos pertinentes ao relacionamento bilateral entre Índia e Brasil foram estimulados pelo IBAS, que possibilitou mais encontros entre os chefes de governo dos dois países. Assim, em 2006, quando o Primeiro Ministro Manmohan Singh veio ao Brasil participar do Encontro de 
Cúpula do IBAS, também reservou parte de sua agenda para tratar de temas bilaterais. "Em realidade, comparados aos acordos assinados pelo IBAS, os que envolveram somente Índia e Brasil foram mais assertivos, demonstrando o nível de maturidade no qual se encontravam as tratativas entre os dois países” (VIEIRA, 2007, p.133).

Outro aspecto importante no relacionamento dos dois países é a abertura do Consulado-Geral do Brasil em Mumbai em 2006, inserido num contexto de abertura de postos diplomáticos em países em desenvolvimento, como resultado de uma política externa tendo em vista a autonomia e a cooperação SulSul.

\section{Aspectos Multilaterais Do Relacionamento Entre Brasil E Índia}

Em função da coordenação na direção de temas comuns entre o Brasil e a Índia, a análise dos aspectos multilaterais das relações entre os dos países será centrada na atuação de ambos nos fóruns internacionais, levando em conta tanto as negociações em organizações como o GATT e, posteriormente, a OMC, quanto a formação de blocos como os BRICS e o IBAS. Assim, será possível considerar as funções de liderança assumidas pela Índia e pelo Brasil a frente dos países em desenvolvimento em fóruns de maior escopo, bem como suas iniciativas para a constituição dos grupos citados anteriormente.

A discussão do papel desempenhado por Índia e Brasil nas negociações da Rodada Uruguai do GATT, entre 1986 e 1994, é fundamental quando se estuda a mudança do paradigma de inserção internacional destes países após as suas respectivas aberturas econômicas. É notável que ambos buscaram uma posição de liderança regional e também frente ao grande bloco de países em desenvolvimento. Guimarães (2005) corrobora esta ideia, considerando que “[...] o Brasil talvez tenha sido, ao lado da Índia, o mais importante e decisivo país em desenvolvimento ao longo dos nove anos de negociações” (GUIMARÃES, 2005, p.14). O mesmo autor considera que "a mudança no posicionamento brasileiro em diversos momentos da Rodada coincide com a posição indiana" (GUIMARÃES, 2005, p. 79), em grande parte porque a economia dos dois países, por ser bastante diversificada, abria novas possibilidades de ganhos no âmbito do GATT, por meio de coalizões mais pragmáticas.

Em linhas gerais, os dois países atuaram juntos no G5 (Brasil, Índia, Argentina, Iugoslávia e Egito), quando buscaram concluir os impasses da rodada anterior antes que se iniciasse uma nova; bem como participaram na liderança do G-10, grupo surgido em 1982 com objetivo de questionar a agenda proposta pelos EUA, deixando de fora da pauta de negociações do GATT o tema dos serviços e propriedade intelectual (VIEIRA, 2007).

Observa-se que com a instituição da OMC em 1995, o Brasil e a Índia seguiram na posição de liderança dos países em desenvolvimento, a exemplo do comportamento durante a Rodada Uruguai. Entretanto, as posições deixaram de ser fruto de coincidências, passando a ser determinadas de maneira concertada entre os dois países. A nova instituição também contribuiu para o surgimento de novas possibilidades que se tornaram uma razão para o aumento do interesse da Índia pelo Brasil. Chakraborty considera que, para os indianos, havia a necessidade de “[...] construir alianças para as negociações 
ocorridas no âmbito da OMC e a convergência de posições em relação a questões como o comércio de serviços, agricultura, barreiras não tarifarias e propriedade intelectual” (CHAKRABORTY, 2005 apud VIEIRA, 2007). O fim da Guerra Fria também representava, para o governo brasileiro, a possibilidade de desenvolver as relações com a Índia de maneira mais desenvolta, sem a restrição dos blocos predominantes no período anterior.

Um fato que deixou evidente a coordenação entre Índia e Brasil foi a discussão a respeito de medicamentos antirretrovirais para tratamento do HIV/Aids no âmbito da OMC em 2001. Nesse ano, o governo brasileiro licenciou a produção doméstica destes medicamentos, com base na exceção garantida pelo Artigo 31 do Acordo TRIPs ${ }^{7}$, gerando a solicitação norte-americana de um painel na OMC contra a lei de patentes brasileira. Entretanto, esta iniciativa foi aclamada na Índia, pela sua própria capacidade de produzir tais medicamentos com custos inferiores aos dos produtos patenteados e pela possibilidade de inserção no mercado africano e brasileiro. Esta primeira aliança entre Índia, Brasil e países africanos foi extremamente produtiva no âmbito da OMC.

Dando continuidade a esta ideia de coordenação política em fóruns multilaterais, o ano de 2003 representa uma virada importante no relacionamento entre o Brasil e a Índia. Esta nova fase se dá principalmente pelo início do governo Lula e pela nomeação de Celso Amorim para o Ministério das Relações Exteriores. Surgem neste ano o Fórum de Diálogo Índia, Brasil e África do Sul (IBAS) - também conhecido como G3 - e o G20, grupo de países em desenvolvimento com foco em políticas voltadas para o setor agrícola, com base na Agenda para o Desenvolvimento proposta em Doha.

Além deste contexto interno, Guimarães considera que desde o fim da Guerra Fria, há um retorno dos grandes países periféricos ao jogo diplomático mundial, valendo-se da definição de Samuel Guimarães para este conjunto de países: "Os grandes Estados periféricos são aqueles países não-desenvolvidos, de grande população e de grande território, não inóspito, razoavelmente passível de exploração econômica e onde se constituíram estruturas industriais e mercados internos significativos.” (GUIMARÃES, 1999, p.21). Em função destas potencialidades que os grandes países periféricos, como o Brasil e a Índia, buscam ter uma atuação menos passiva na estruturação da ordem internacional.

Além deste alinhamento em temas multilaterais, também cabe ressaltar outras semelhanças entre os três países, como seu papel de liderança regional e o desejo de enfrentar os problemas sociais. O objetivo, segundo Celso Amorim, era de “[...] transformar essa coincidência virtual numa cooperação real.” (ENTREVISTA CONJUNTA, 2003 apud BUENO, 2010).

Quando da sua constituição, os países do IBAS (ou G3) assinalaram os principais pontos de coordenação política. Segundo Vizentini (2009),

\footnotetext{
${ }^{7}$ O Acordo TRIPs, do inglês Agreement on Trade-Related Aspects of Intellectual Property Rights, é um tratado internacional resultante das discussões da Rodada Uruguai do GATT. O assunto da propriedade intelectual foi incluído na agenda das negociações por pressão de países desenvolvidos, contrariando o desejo dos países em desenvolvimento liderados pelo Brasil e pela Índia. De acordo com Silveira "o Acordo sobre Aspectos dos Direitos de Propriedade Intelectual Relacionados ao Comércio [...] foi o primeiro a introduzir a propriedade intelectual no sistema multilateral de comércio, visando estabelecer requisitos mínimos de proteção a propriedade intelectual, com validade para todos os países membros da OMC” (SILVEIRA, 2011, p.37).

8 ENTREVISTA CONJUNTA. 2003. Disponível em: <http://www.mre.gov.br/portugues/politica_externa/grupos/ibas/entrevista.asp>. Acesso em: 03 nov. 2005.
} 
[...] os três países acordaram a defesa dos seguintes princípios: a importância do respeito às regras do Direito Internacional, do fortalecimento da Organização das Nações Unidas e do Conselho de Segurança e da prioridade ao exercício da diplomacia como meio para a manutenção da paz e da segurança internacionais. Reafirmaram a necessidade de combater as ameaças à paz e à segurança internacionais em conformidade com a Carta das Nações Unidas e com os instrumentos jurídicos de que são parte Brasil, Índia e África do Sul. Também defenderam a reforma da ONU, em particular o Conselho de Segurança. A esse respeito, frisaram a necessidade de o Conselho ser expandido nas categorias de membros permanentes e não-permanentes, com participação de países em desenvolvimento, em ambas categorias. Concordaram em conjugar esforços no sentido de aumentar a eficiência da Assembleia Geral e do Conselho Econômico e Social das Nações Unidas. (VIZENTINI, 2009, p.22).

Apesar de seu viés eminentemente político, a formação do IBAS ocorreu impulsionada por uma onda de crescimento do comércio entre os três países. Em 2002, o comércio entre Brasil e a Índia foi da ordem de 1,2 bilhões de dólares, um crescimento de $48 \%$ em relação ao ano anterior. África do Sul e a Îndia, por sua vez, registraram trocas de 1,4 bilhões de dólares, um número $40 \%$ maior que no ano anterior. Por fim, o Brasil e a África do Sul tiveram intercambio da ordem de 1,1 bilhões de dólares. Há, portanto, uma mescla de objetivos políticos e econômicos na organização, o que lhe confere uma flexibilidade peculiar (VIEIRA, 2007).

O que marca a importância do G20 é uma mudança na postura destes países nas conferências da OMC, que passa de ser um veto reativo para uma agenda proativa, com capacidade técnica baseada em informações apuradas, o que permitia, mais do que dizer "não", propor alternativas viáveis ao impasse. O que chama a atenção é justamente isto: ao invés de negociarem apenas em torno de fatores ideacionais e identitários, como ocorria com as coalizões de bloco do passado, tais como o movimento dos não-alinhados, o G20 negociou também como uma coalizão temática em torno de questões instrumentais (OLIVEIRA, 2005).

Ainda em um contexto de iniciativas multilaterais recentes com envolvimento do Brasil e da Índia, é fundamental falar dos BRICS. O grupo, cuja sigla foi inicialmente formulada pelo banco Goldman Sachs como instrumento de marketing financeiro, estabeleceu-se como mecanismo político diplomático diferenciando-se de outros grupos de países como por exemplo os Next Eleven (Indonésia, Bangladesh, Egito, Irã, México, Nigéria, Paquistão, Filipinas, Coreia do Sul, Turquia e Vietnã) e os CIVETS (Colômbia, Indonésia, Vietnã, Egito, Turquia e África do Sul).

A primeira reunião formal de chanceleres dos BRICS ocorreu em maio de 2008, representando o surgimento do grupo como entidade político-diplomática. Nesta reunião se produziu um Comunicado Conjunto, em que se destacam os compromissos pelo fortalecimento do multilateralismo, pela necessidade de reforma da $\mathrm{ONU}$, pela necessidade de assegurar oportunidades iguais para o desenvolvimento de todos os países e pelo apoio à solução de disputas por meios políticos e diplomáticos. Além destes compromissos, haviam posições coincidentes quanto ao desarmamento, não proliferação, terrorismo e efeitos das mudanças climáticas (REIS, 2012). 
A entrada oficial da África do Sul no grupo se deu na Terceira Cúpula dos BRICS, em abril de 2011. O ingresso sul-africano ampliou a representatividade dos países do grupo, consolidando o mesmo enquanto foro político integrado por representantes de quatro continentes.

Pode-se dizer que o bloco funciona em dois pilares de atuação, que vem sendo fortalecidos: a coordenação em fóruns multilaterais sobre temas de interesse comum e a construção de uma agenda de cooperação intra-bloco, especialmente em temas ligados ao desenvolvimento. O compromisso com estes temas ficou evidente em julho deste ano, quando os governos dos cinco países assinaram o acordo que criou o Banco de Desenvolvimento dos BRICS, com objetivo de financiar projetos de infraestrutura e desenvolvimento, seguindo a ideia do Fundo IBAS.

\section{Conclusões}

O fim da década de 1980 e o início da década de 1990 marcam um ponto de inflexão importante na dinâmica do Sistema Internacional, dominado pela dicotomia Leste-Oeste por grande parte do século XX. Com a desintegração da União Soviética e o consequente fim da Guerra Fria, a nova ordem internacional que se estabelece é pautada pela multipolaridade. Neste sentido, as potências médias, como o Brasil, passam a buscar novos parceiros estratégicos, com o objetivo de maximizar sua influência no sistema internacional e minimizar suas vulnerabilidades - e é dentro deste contexto que emerge a chamada cooperação Sul-Sul, em que potências emergentes compartilham objetivos e mecanismos para solução de problemas.

Assim, este artigo considerou que a aproximação entre Brasil e Índia é fortemente influenciada por esta tendência mundial de cooperação entre países em desenvolvimento. Além das estruturas do sistema internacional estarem mais favoráveis a este tipo de parceria, a aproximação dos dois países também deve ser entendida como fruto dos seus respectivos processos de abertura e liberalização da economia, condicionados pela ascensão de correntes de pensamento neoliberais na época e pela forte participação estatal em ambas as economias que conduziram o processo.

O processo de abertura comercial do Brasil se insere no contexto de redemocratização do país, depois de mais de vinte anos de regime militar. Os dez primeiros anos de governo civil foram marcados pela busca de superação da crise econômica em que o Brasil se encontrava, simbolizada pelos altos níveis de inflação registrados (passando dos $200 \%$ ao ano) e pela crescente dívida externa. O fracasso dos programas de estabilização econômica implementados pelo governo de José Sarney (1985 - 1990) tornou a situação econômica do país insustentável, sendo um dos fatores que possibilitaria a eleição de Fernando Collor de Mello a presidente em 1989.

De fato, o ideário liberalizante permeou as ações econômicas do governo Collor (1990 - 1992), tanto no sentido de estabilizar a moeda - através do Plano Brasil Novo, que, como os planos anteriores, também foi malsucedido - quanto na busca por integrar o Brasil ao "Primeiro Mundo" por meio do comércio internacional. Mais do que o Plano Collor, o verdadeiro legado deste breve governo foi a reorientação econômica e externa do Estado promovida no período, com projetos de integração econômica e com a Política Industrial e de Comércio Exterior, além do fim das restrições não tarifárias para importações e 
exportações; a partir deste momento, podemos entender que o Brasil abandona a noção varguista de industrialização nacional por substituição de importações.

Assim como a abertura econômica brasileira, a liberalização da economia indiana também pode ser vista como resultado da situação do país na década de 1980. Com a independência do Reino Unido em 1947, a Îndia optou por uma via econômica mais fechada, priorizando a industrialização por substituição de importações e ampliação da ação do governo em áreas consideradas estratégicas da economia.

É neste período pós-independência que são lançados os primeiros Planos Quinquenais, com o objetivo de atingir metas de crescimento e modernização, além de maximizar os recursos produtivos disponíveis na Índia. Ao longo das décadas de 1950 e 1960, gradativamente o governo passou a intervir cada vez mais na economia do país, restringindo importações, priorizando o setor de bens de capital e realizando nacionalizações de diversas empresas. Além de aumentar o crescimento do PIB, também havia uma preocupação em diminuir os níveis de pobreza no país.

A partir dos anos 1980 começa a ficar evidente que este modelo de desenvolvimento, bastante autárquico e com alto grau de intervenção estatal, não seria sustentável por muito tempo. Com a ascensão de Rajiv Gandhi (1984 - 1989) ao posto de primeiro-ministro, a lógica de administração econômica indiana muda significativamente, marcando o início das reformas liberalizantes que atacaram o controle doméstico da produção e do investimento e o controle do comércio externo, além da implementação de incentivos às exportações.

Esse momento de abertura econômica nos dois países pode ser entendido como um ponto de inflexão nas suas respectivas políticas econômicas e de comércio exterior, marcando uma mudança nas suas lógicas de inserção no sistema internacional. A partir daí, é possível observar um movimento de aproximação entre os mesmos. Os esforços neste sentido devem ser entendidos tanto como frutos da conjuntura internacional - com o fim da Guerra Fria, a ascendência de correntes neoliberais e a emergência do Sul global - quanto das conjunturas internas dos dois países.

O movimento de aproximação entre os dois países, apesar de deliberado, foi bastante lento e gradual, acentuando-se a partir de 2003; entretanto, a maior proximidade se dá no campo políticodiplomático, com a criação de fóruns como o IBAS e o BRICS, além da articulação nas rodadas da OMC, onde Brasil e Índia atuaram como lideranças a frente dos países subdesenvolvidos. O comércio entre os dois países, ainda que mostre uma tendência de crescimento ao longo das décadas de 1990 e 2000, não atingiu resultados tão significativos quanto aqueles no âmbito político.

Além disso, a proximidade entre Brasil e Índia proporcionada a partir de 2003, com a articulação do IBAS e do G20 na OMC, teve uma influência direta na corrente de comércio entre os dois países - ou seja, a intensificação das relações comerciais indo-brasileiras é um subproduto da cooperação bilateral e das iniciativas de integração multilaterais que envolvem os dois países. A partir dessas percepções, é possível afirmar que os laços comerciais entre Brasil e Índia são bastante tênues quando comparados aos avanços políticos e diplomáticos logrados ao longo do período estudado, desta forma, fica claro que o aumento do comércio entre os dois países é produto direto das iniciativas de cooperação político-diplomática. 


\section{REFERÊNCIAS}

BRASIL. Ministério do Desenvolvimento, Indústria e Comércio Exterior. Alice Web. 2014. Disponível em: <http://aliceweb.mdic.gov.br/>. Acesso em: 12 nov 2014.

BRASIL. Ministério das Relações Exteriores. Comunicado Conjunto Brasil - Índia. 21/10/2003. Disponível em: $\quad$ http://www.itamaraty.gov.br/sala-de-imprensa/notas-a-imprensa/2003/10/21/comunicadoconjunto-brasil-india-nova-delhi-21-de>. Acesso em: 12 nov. 2014.

BUENO, Adriana. Os três pilares institucionais do Fórum de Diálogo Índia-Brasil-África do Sul (IBAS): coordenação política, cooperação setorial e Fundo IBAS. (Axe IX, Symposium 33). In: Independencias-Dependencias-Interdependencias, VI Congreso CEISAL 2010. 2010.

GUIMARÃES, Feliciano de Sá. “A Rodada Uruguai do GATT (1986-1994) e a Política Externa Brasileira: acordos assimétricos, coerção e coalizações”. Dissertação (Mestrado em Relações Internacionais) Instituto de Filosofia e Ciências Humanas, UNICAMP, Campinas, 2005.

GUIMARÃES, Samuel Pinheiro. Quinhentos anos de periferia: uma contribuição ao estudo da política internacional. Porto Alegre: Editora Da Universidade Federal Do Rio Grande do Sul, 1999.

HAFFNER, J. A. H.; BARBOSA, Marcel Jaroski. Análise das relações bilaterias entre o Brasil e a Índia pósdécada de 1990. In: Ministerios de Relações exteriores, Fundação Alexandre Gusmão. (Org.). IV Seminário sobre pesquisas em relações econômicas internacionais. 1ed.Brasília: Brasil, 2012, v. , p. 141-164.

HAFFNER, J. A. H. ; MONTEIRO, L. L. V. . As relações econômicas entre Índia e Brasil: Trajetória e perspectivas. In: 3ro Encontro ABRI, 2011, Sâo Paulo. Associação Brasileira de Relações Internacionais, 2011.

KUME, Honório; PIANI, Guida; MIRANDA, Pedro. Índia-Mercosul: Perspectivas de um Acordo de Preferências Comerciais. Rio de Janeiro: Instituto de Pesquisa Econômica Aplicada-IPEA, Texto para Discussão n. 1120, 2005.

OLIVEIRA, Marcelo Fernandes de. Alianças e coalizões internacionais do governo Lula: o Ibas e o G-20. Revista Brasileira de Política Internacional, Rio de Janeiro, v. 48, n. 2, p. 55-69, 2005.

REIS, Maria Edileuza Fontenele. BRICS: surgimento e evolução. In: BAUMANN, Renato (Org.). O Brasil e os BRICS. Brasília: FUNAG, p. 31-49, 2012.

SILVA, Luís Inácio Lula da. Discurso na solenidade de abertura do Encontro "Brasil - Índia Desenvolvimento Sustentável: Perspectivas e Possibilidades. Nova Delhi, 2004. Disponível em: <http://www.itamaraty.gov.br/divulg/documentacao-diplomatica/publicacoes/resenha-de-politicaexterior-do-brasil/resenhas/resenha-n94-1sem-2004>. Acesso em: 02 nov. 2014.

SILVA, Luís Inácio Lula da. Índia-Brasil-África do Sul: o fórum que veio para ficar. O Globo, Rio de Janeiro, 17 out. 2007. Disponível em: <http://www.itamaraty.gov.br/sala-de-imprensa/discursos-artigosentrevistas-e-outras-comunicacoes/presidente-da-republica-federativa-do-brasil/0465367928399artigo-do-presidente-luiz-inacio-lula-dasilva/?searchterm=desenvolvimento\%20sustent\%C3\%A1vel\%20\%C3\%ADndia>. Acesso em: 02 nov. 2014.

VIEIRA, Maíra Baé Baladão. Relações Brasil-Î́ndia (1991-2006). 2007. 227 f. Dissertação (Mestrado) Universidade Federal do Rio Grande do Sul, Porto Alegre, 2007.

VIZENTINI, Paulo Fagundes. O G-3 e o G-20: o Brasil e as novas coalizões internacionais. Relações internacionais do Brasil: temas e agendas, Porto Alegre, v. 2, 2009.

Recebido em 09 de agosto de 2015. Aprovado em 10 de novembro de 2015. 


\title{
RESUMO
}

O presente trabalho busca analisar a evolução das relações comerciais entre Brasil e Índia, considerando o início da década de 1990 como ponto de inflexão neste relacionamento, em função de suas respectivas aberturas econômicas e das mudanças no cenário internacional. As mudanças econômicas nos dois países possibilitaram uma aproximação lenta e gradual entre os mesmos, e sob esta ótica se consideram os aspectos comerciais e político-diplomáticos que condicionaram as relações indo-brasileiras, nos âmbitos bilateral e multilateral.

Palavras-chave: Brasil; Índia; IBAS; BRICS;

\begin{abstract}
This paper seeks to analyze the evolution of commercial relations between Brazil and India, considering the early 1990s as a turning point, due to their liberating economics reforms and to the changes in the international context. The changes in both economies allowed a slow and gradual approach between them, and, within this perspective, this paper considers the commercial and political-diplomatic aspects that conditioned the Indo-Brazilian relations, in bilateral and multilateral scope.
\end{abstract}

Keywords: Brazil; India; IBSA; BRICS; 